\title{
Feijóo y los Españoles Americanos
}

GIMPATICA es la figura de aquel ilustre benedictino del siglo XVIII, el P. Benito Jerónimo Feijóo, que en el retiro de su monasterio de Oviedo dedicó gran parte de su vida a destruir con sus escritos los errores populares del vulgo, a despertar interés en los adelantos y progresos científicos de su tiempo y a encauzar las energías intelectuales de los españoles hacia la ciencia y cultura verdaderas. Todo error o conseja popular era para él un incentivo de lucha, tanto más si el error prevalecia entre el vulgo "de bonete y capilla".

Entre los varios temas que preocuparon a Feijóo hay uno que es de interés para la historia de las relaciones de simpatía y aprecio intelectuales entre España y los paises de América, colonias entonces del imperio español. En varias partes de sus obras hay referencias a América y a los hispanoamericanos de su tiempo, o "españoles americanos" como él los llama. Comprendía en estos términos a los españoles establecidos en América, a sus descendientes; los criollos, y creo que también a los mestizos. 1 Para Feijóo los criollos o mestizos de América eran tan españoles como los naturales de la península. Hay que tener en cuenta este dato para comprender bien la importancia de las opiniones de Feijóo, que ya en el siglo XVIII supo apreciar el mérito y excelentes cualidades de la población colonial y tuvo el valor de ser su campeón contra errores populares establecidos, al parecer, en España.

La América española produjo, desde los primeros tiempos de la conquista, espiritus extraordinarios en las letras y profesiones que no pudieron menos de ser notados y admirados en España. A pesar de envidias, prejuicios y obstáculos, sus méritos fueron re- 
conocidos. E1 inca Garcilaso de la Vega, el mexicano Alarcón, Sor Juana Inés de la Cruz, son ejemplos que vienen en seguida a la memoria. Otros hombres eminentes hubo, como Sigüenza y Góngora en México y Peralta y Barnuevo en el Perú que, aunque de famā casi circunscrita a sus respectivas regiones, fueron también conocidos y alabados por los españoles sinceros y desinteresados.

No hay duda de que los españoles peninsulares se consideraban por derecho propio los verdaderos representantes de la cultura española. Tacañamente concederían excelencia en las letras o en las profesiones a los españoles americanos que venían a España. Esto era natural y excusable. En España estaban las antiguas y veneradas universidades, con sus Estudios mayores y numerosos Colegios; de España salían principalmente los maestros, doctores y licenciados que iban a ocupar las cátedras de las Universidades y Estudios de América. El español americano o criollo que aspiraba a descollar en la península, o aun en su propio país, tenía que vencer obstáculos muy grandes con sus talentos y aplicación. Quizás este incentivo de igualar o superar la primacía establecida del español peninsular haría que muchos americanos cultivaran sus dotes con extraordinario esfuerzo y se aplicaran a. los estudios con redoblada intensidad. Ello es que la proficiencia y distinción de los hispanoamericanos en toda clase de estudios llegó a ser tan notable y general, que vino a convertirse en tradición. Pero al mismo tiempo nació también una leyenda: el hispanoamericano desplegaba una inteligencia clara y brillante en. su juventud, mas esta inteligencia caducaba temprano, y en la edad madura perdia su esplendor y viveza, si es que no se trocaba en mentalidad obtusa o chocha.

Feijóo se hizo cargo de estas opiniones en el segundo tomo de su Teatro crítico (1728), cuando, al hablar de la cultura y habilidad natural de los sujetos de varias: naciones en su Discurso "Mapa intelectual y cotejo de naciones", dice de los americanos: "Muchos han observado que los criollos o hijos de españoles que nacen en aquella tierra son de más viveza intelectual que los que produce España. Lo que añaden otros, que aquellos ingenios así como amanecen más temprano también se anochecen más presto; no sé que esté justificado"..2

Feijóo no se detiene a refutar el error que menciona de pasada, quizás por no creer que estuviera muy extendido. Pero dos años 
más tarde, en el tomo IV del Teatro (1730), dedicó todo un Discurso a refutar la leyenda de la temprana decadencia mental del americano, el titulado "Españoles Americanos". Su motivo no fué otro que salir a la defensa de la verdad. Una pluma como la suya, "destinada a impugnar errores comunes, nunca se empleará más bien que cuando la persuasión vulgar... es perjudicial e injuriosa a alguna República o cúmulo de individuos que hagan cuerpo considerable en ella". 3

¿Por qué se decidió Feijóo a escribiŕ esta defensa de los hispanoamericanos? Habia llegado a su noticia que en Madrid era corriente la creencia susodicha respecto a ellos, aun entre personajes de influencia y distinción en la corte, pues un caballero de gran importancia en ella le rógó que desvaneciese tal error en sus escritos. 4 Dice Feijóo: "Habiendo yo tocado en el segundo tomo la opinión común de que los criollos o hijos de españoles que nacen en la América así como les amanece más temprano que a los de acá el discurso también pierden el uso de él más temprano, un caballero de ilustre sangre, de alta discreción, de superior juicio, de inviolable veracidad y de una erudición verdaderamente portentosa en todo género de noticias... me avisó que esta opinión común debia comprenderse entre los errores comunes, proponiéndome tan concluyentes pruebas contra ella, que si añado algunas de mi reflexión, noticia y lectura, será, no porque aquéllas no sobren para el desengaño, sino para dar alguna extensión al presente discurso, en el cual pretendo desterrar una opinión tan injuriosa a tantos españoles (algunos de alto mérito) que la transmigración de sus padres o abuelos hizo nacer debajo del cielo americano". 5

- Procede luego Feijóo a demostrar que hubo anteriormente y había en su tiempo hombres distinguidos por su inteligencia y por el desempeño de sus altos cargos, todos criollos, todos de edad avanzada, que brillaron por la lucidez de su inteligencia ya en España, ya en América. Cita al que fué Arzobispo de Santiago, don Fr. Antonio de Monroy, que llegó a la edad nonagenaria; al entonces Consejero de Hacienda don José de los Ríos, de ochenta y seis años, desempeñando su cargo "con la asistencia y conocimiento que si no tuviese más de cincuenta"; al Marqués de Villarrócha, septuagenario, Presidente que había sido de Panamá y "ha cuatro años que vino del mar del Sur por las Filipinas y el cabo de Buena Esperanza a 
Holanda; es insigne matemático e instruído en toda buena literatura"; al Virrey de México, el Marqués de Casa-Fuerte, "cuya adelantada edad se puede colegir de que ha más de cincuenta años que está sirviendo a su Majestad en varios empleos políticos y militares... quien, bien lejos de ser notado de que los años le hayan deteriorado el juicio, está sumamente aplaudido por su cristiana y prudente conducta, de modo que es voz común en México que no se vió hasta ahora gobierno como el suyo"; al Capitán General de la Real Armada, don Pedro Corvete, "sin que jamás decaeciese por los afios (que eran muchos) de la entereza de genio y hermosura de espiritu que tuvo"; y al Inquisidor Decano en Toledo, el señor Ovalle, "que ya pasa de sesenta años".

Es notable el párrafo que dedica al enciclopédico peruano Peralta y Barnuevo, que por constituir un documento de apreciación justa y por haber contribuido a esparcir en España la fama de este extraordinario criollo, merece citarse entero: "En Lima reside Don Pedro Peralta y Barnuevo, Catedrático de Prima de Matemáticas, Ingeniero y Cosmógrafo mayor de aquel reyno: sujeto de quien no se puede hablar sin admiración, porque apenas (ni aun apenas) se hallará en toda Europa hombre alguno de superiores talentos $y$ erudición. Sabe con perfección ocho lenguas y en todas ocho versifica con notable elegancia. Tengo un librito que poco ha compuso, describiendo las Honras del Señor Duque de Parma, que se hicieron en Lima. Está bellamente escrito y hay en él varios versos suyos harto buenos en latín, italiano y español. Es profundo matemático, en cuya facultad o facultades logra algunos créditos entre los eruditos de otras naciones, pues ha merecido que la Academia Real de Ciencias de París estampase en su Historia algunas observaciones de eclipses que ha remitido; y el Padre Luis Feville, doctísimo Mínimo y miembro de aquella Academia, en su Diario que imprimió en tres tomos en cuarto, le celebra mucho. Lo mismo hace Monsieur Frezier, Ingeniero francés, en su Viaje impreso. Es historiador consumado tanto en lo antiguo como en lo moderno; de modo que sin recurrir a más libros que los que tiene impresos en la biblioteca de su memoria satisface a cuantas preguntas se le hacen en materias de Historia. Sabe con perfección (aquella de que el presente estado de estas facultades es capaz) la Filosofía, la Química, la Botánica, la Anatomía y la Medicina. Tiene hoy sesenta y ocho años 
o algo más : en esta edad ejerce con sumo acierto no sólo los émpleos que hemos dicho arriba, mas también el de Contador de cuentas y particiones de la Real Audiencia y demás de la ciudad; a que añade Ia ocupación de Presidente de una Academia de Matemáticas y Elocuencia que formó a sus expensas. Una erudición tan vasta, es acompañada de una crítica exquisita, de un juicio exactísimo, de una agilidad y claridad en concebir y explicarse admirables. Todo este cúmulo de dotes excelentes resplandecen y tienen perfecto uso en - la edad casi septuagenaria de este esclarecido criollo. 6

Por no ser prolijo omitiré la mención de otros criollos distiguidos que nombra Feijóo para soportar su defensa de los hispanoamericanos. El que éstos fueran todos conocidos y celebrados en España en su tiempo, movió a Feijóo a incluirlos en su Discurso, pues "sólo se propusieron aquéllos que sus sobresalientes méritos y empleos hicieron recurrir más presto a la memoria, en que también se tuvo la atención de nombrar sujetos tan conocidos que sea a todos fácil la comprobación de que la edad no indujo en su juicio el menor detrimento".

Pero no se contenta con esto. Indaga las causas de la supuesta precocidad mental de los hispanoamericanos. Después de estudiar el caso detenidamente, de pedir información a personas que habían vivido en América, llega a la conclusión de que "no es menos falso que en ellos amanezca más temprano que en los europeos el discurso, que el que se pierda antes de la edad correspondiente". La causa, según Feijóo, es que en América los jóvenes empezaban sus estudios en edad tierna y había mayor cuidado y empeño en su aprovechamiento intelectual. "Yo me he informado exactamente sobre esta materia" - dice, al darnos en detalle los informes recogidos por él, de los usos y métodos seguidos en América en la educación de la juventud.

"Sábese, dice, que en la América por lo común a los doce años y muchas veces antes, acaban de estudiar los niños la gramática y retórica y a proporción en años muy jóvenes se gradúan en las Facultades mayores. De aquí se ha inferido la anticipación de su discurso; siendo así que este adelantamiento se debe únicamente al mayor cuidado que hay en su instrucción y mayor trabajo a que los obligan, y proporcionalmente en los Estudios mayores sucede lo mismo. Acostúmbrase por allá poner a estudiar los niños en una 
edad muy tierna. Lo regular es comenzar a estudiar gramática a los seis años, de suerte que a un mismo tiempo están aprendiendo a escribir y estudiando; de que depende que por la mayor parte son malos plumarios, siendo el mayor conato de los padres que se adelanten en los estudios; por cuyo motivo los precisan a una aceleración algo violenta en la gramática, no dejándoles tiempo, no sólo para travesear, mas ni aun casi para respirar:

"De este modo no es maravilla que a los doce años, y mucho antes, empiecen a estudiar Facultades mayores. Estas se estudian por los seculares en Colegios, de los cuales los de la fundación real están a cuenta de los Padres de la Compañía. No escriben curso alguno, sino que estudian alguno impreso, pero no a su arbitrio, porque (a) cada Colegial graduado se le señala cierto número de discipulos, a quienes explica todo to que han de estudiar, $y$ tomarles juntamente la lección, como en la gramática, castigando a los que no lo cumplen, sin exceptuar la vapulación que es el castigd ordinario de los imberbes. Estudien lo que estudiaren, mientras son cursantes sólo el domingo pueden salir después de haber estudiado hasta las nueve del día; pero aun esto no se permite si las lecciones de la semana no han sido buenas, en cuyo caso todo el día de do mingo se less obliga a estudiar. A la noche siempre se recogen a las seis y hay stu hora de conferencia antes de cenar, tanto los días festivos como los feriales. Juntas todas las vacaciones que hay en el año sólo componen un mes; por lo cual en dos años solos absuelven toda la Filosofía ; pero echada la cuenta, según la práctica de las Universidades de España, que en cada año tienen casi seis meses de vacación, mayor tiempo dan al estudio de la Filosofía allá que acá. Y si se hace cómputo del exceso en el número de horas que estudian cada día y de lo que se añade en los días de fiesta, sale el tiempo más que duplicado. Lo mismo se hace en las demás Facultades respectivas. Conque bien mirado todo, el aprovechamiento anticipado de los criollos en ellas no se debe a la anticipación de su capacidad, si a la anticipación de estudio y continua aplicación a él. Si en España se practicara el mismo método, es de creer que a los veinte años se verían por acá Doctores graduados in utroque como en la América." 7

Duélele a Feijóo que estas prácticas no existieran en España, prácticas que a su parecer contribuían a moderar las pasiones de la 
juventud americana. "En nuestras Universidades, añade, bien lejos de marchitarse en los cursantes la viciosa fecundidad de las pasiones, se cultivan infelizmente en los intervalos del estudio y brotan furiosamente antes de tiempo, de modo que vuelven a las casas de sus padres aquellos jóvenes mucho peores que salieron de ellas; y a tanto cuanto que ayude una siniestra indole, al acabar sus cursos, son mejores galanteadores y. espadachines que filósofos." No fué Feijóo el primero en hacer notar el gran número de hispanoamericanos extraordinarios, como él mismo nos lo dice al citar la opinión de muchos autores 8 que los declarabán, no sólo iguales a los europeos, sino superiores en muchos casos. Conforma él esta opinión diciendo que "entre los hombres eruditos que ha tenido nuestra España de dos siglos a esta parte no encuentro alguno de igual universalidad a la de D. Pedro Peralta... Si discurrimos por las mujeres sabias y agudas, sin ofensa de alguna, se puede asegurar que ninguna dió tan altas muestras (que saliesen a la luz pública) como la famosa monja de México, Sor Juana Inés de la Cruz". 9

Laméntase Feijóo de que suceda el caso de haber grandes ingenios hispanoamericanos completamente desconocidos en España. Cita el nombre del distinguido limeño don José Pardo de Figueroa, nombre que vió por primera vez, no en alguna obra española, sino en un poema latino, "Proedium Rusticum", del jesuíta francés Jacobo Vaniere. Esta noticia excitó la curiosidad de Feijóo; hizo él diligencias para informarse de sus méritos y erudición y acabó por entablar amistad y correspondencia epistolar con él. "El aprecio que hace de él el sabio jesuita es tan alto que le propone como ejemplar bastante por sí para acreditar de excelentisimos los ingenios de Lima. Yo, después que le he comunicado, no sólo puedo suscribir aquel elogio, pero darle más dilatada extensión, por la admirable universalidad de noticias que me representan sus cartas en todo género de materias, acompañada de delicado discurso, elocuente estilo, crítica exacta, juicio profundo... (cartas que) son muchas y muy largas y conservo como un tesoro de toda erudición; y para testimonio público de mi agradecimiento confieso y protesto aquí que me han dado mucha luz en muchas materias que toco en este tomo". 10 
Ya en el siglo XVII, sesenta y tres años antes que Feijóo escribiera su defensa de los españoles americanos, se había consignado el hecho antes mencionado de que se hiciera poco aprecio en España de las dotes intelectuales de los criollos. En el Prólogo a la Historiä de Tobias (1667), escrita por don Antonio Peralta Castañeda, Catedrático de Prima de los Reales Estudios de la Puebla de los Angeles, se lee: "Está entendido en este Hemisferio que se miran en la Europa con poco aprecio sus obras porque tienen poco crédito sus letras; $y$ en esto como en otras cosas están ofendidos sus sujetos. De la escuela de Alcalá soy discípulo... y, sin comparar esto con aquello puedo asegurar que comúnmente hay en este Reyno en menor concurso más estudiantes adelantados, y que en algunos he visto lo que nunca vi en iguales obligaciones en España; y no refiero singulares, porque no se tenga a pasión referir prodigios. Todo lo he dicho por llegar a desagraviar este Reyno (México) de una calumnia que padece con los que saben que (de) mozos son prodigiosos los sujetos; pero creen que exhalan sus capacidades y se hallan defectuosos en los progresos. Pobres de ellos que los más vacilan de la necesidad, desmayan de falta de premios, y aun de ocupaciones, y mueren de olvidados que es el más mortal achaque del quie estudia". 11

En las razones mencionadas en estas últimas frases ve también Feijóo las causas del error común acerca de la decadencia mental de los americanos: las muchas dificultades que encontraban para hacer fortuna en la carrera de las letras, el tener que abandonar los estudios para encontrar medios de subsistencia en ocupaciones más asequibles, el olvido y abandono en que se encontraban los criollos cuando tenian que competir con los españoles peninsulares. $Y$ añade: "Nótese que este autor había nacido en España y estudiado en Alcalá. Así no se debe reputar por interesado, ni en lo que elogia a los ingenios de la América, ni en la apología que hace por ellos contra el error común de su pronta disipación". 12

Feijóo continuó durante toda su vida apreciando el mundo literario hispanoamericano y manifestando siempre que venía al caso - su admiración generosa por todo lo de América. Aun en su ancianidad, treinta y dos años después de haber hecho su defensa de los hispanoamericanos, consigna en el tomo V de sus Cartas (1760), con ocasión de comentar el libro Reflexiones sobre la despoblación 
de España, escrito por un hispanoamericano: "Dicho escrito me confirma más en el asiento de una verdad que mucho tiempo ha por el trato, en parte de palabra y mucho más por escrito, con algunos caballeros indianos habia comprendido: esto es, que la cultura en todo género de letras humanas entre los que no son profesores por destino, florece más en la América que en España; los que con esta misma. expresión me certificó el Sr. Conde de las Torres cuando en su segundo arribo del Perú a nuestra península, sólo por favorecerme, tomó de Galicia el rodeo por Oviedo para la Corte". 13

Es notable el aprecio que Feijóo hizo de Sor Juana Inés de la Cruz. Al enumerar las mujeres famosas en la historia en su Discurso "Defensa de las mujeres", nos da un juicio bastante acertado de los méritos de la monja mexicana. Cosa muy notable si consideramos la severidad que manifiesta en muchas partes de sus obras con otros poetas. Los modelos supremos de Feijóo en poesía eran los clásicos latinos y algunos pocos españoles del siglo de oro. Teniendo en cuenta la hojarasca poética que llovió sobre España y América desde fines del siglo XVII y las aspiraciones neoclásicas que se iban imponiendo en el XVIII, Feijóo supo mantener una actitud sincera y justa en la apreciación de Sor Juana, apreciación que faltó en Nicasio Gallego años más tarde, cuando la juzgó según las normas rigurosas del clasicismo reinante, sin sentir la nota tierna y humana de la famosa mexicana. Menéndez y Pelayo creé que las mejores poesías de Sor Juana son dignas del alto juicio que le merecieron a Feijóo. 14 También hay que notar que la universalidad de conocimientos de Sor Juana constituía para él su mérito más grande; no podía ser de otro modo, dado el espiritu de Feijóo, universal, ávido de curiosidad científica, enciclopédico y poco poético. "La célebre monja de México, dice, Sor Juana Inés de la Cruz, es conocida de todos por sus eruditas y agudas poesías : $y$ asi es excusado hacer su elogio. Sólo diré que lo menos que tuvo fué el talento para la poesía, aunque es el que más se celebra. Son muchos los poetas españoles que la hacen grandes ventajas en el numen, pero ninguno acaso la igualó en la universalidad de noticias de todas facultades. Tuvo naturalidad, pero faltóle energía. La crisis del sermón del P. Vieyra acredita su agudeza". 15

Los críticos de Feijóo (Mañer, Soto-Marne); que no dejaron punto $\sin$ atacar en los escritos del benedictino, trataron de destruir 
sus argumentos en, defensa de los hispanoamericanos. E,videntemente la leyenda contra ellos tenia bastantes partidarios. Aquel erudito y alter ego de Feijóo, el P. Martín Sarmiento, dedica nueve páginas de su "Demostración crítico-apologética" a defender a su maestro y amigo y a destruir por completo las consejas corrientes é contra de los hispanoamericanos, 16 contra las cuales también presentó un Memoriàl al Rey el mexicano don Juan Antonio de Ahumada, con el título de "Representación político-legal", viniendo él mismo de México a Madrid para este efecto. En defensa de los mexicanos decía este Memorial que "la astuta sagacidad de sus émulos maquinó varias trazas, disputando primero su idoneidad, teniéndolos apenas por dignos del nombre de racionales... Aun por incapaces de órdenes los han juzgado, sólo por haber alli nacido..." Después que se vió a luces claras que los hispanoamericanos eran tan capaces para todo como cualquier europeo, inventaron nueva calumnia: la de que desde los treinta años en adelante se les iba trastornando la racionalidad. La explicación era que "hasta el tiempo de los treinta años trabajan (en sus estudios) con honra y empeño, pero, llegando a él, totalmente desesperan del premio. De los que viven con alguna esperanza o que tienen empleo de letras, no se verificará tal proposición". 17

Se continuaban en este Memorial las quejas, ya notadas por Menéndez y Pelayo, de "los malhumorados y empobrecidos descendientes de los conquistadores (criollos o mestizos) contra los nuevos aventureros que venían de España y que por más hábiles o más activos se iban alzando con todos los provechos". 18

No hay duda que los hispanoamericanos, y especialmente los mexicanos, quedaron agradecidos a Feijóo por la defensa de su causa. Sus libros fueron extensamente leídos y grandemente apreciados en toda América y en Filipinas. Algunos americanos tuvieron ocasión de mostrarle su agradecimiento en las aprobaciones encomiásticas que escribieron para varios tomos de sus obras. El doctor Francisco Antonio Valleja (mexicano), en la "Aprobación": al primer tomo de las Cartas eruditas, declaró su fama "en ambos hemisferios". Igualmente generosos en sus alabanzas fueron don Diego Rodríguez de Rivas, arcediano de la Iglesia Metropolitana de Guatemala, y don Tomás de Querejara, catedrático de la Real Universidad de Lima, en las aprobaciones del tercer tomo de las Cartas. 
Pero el que directamente correspondió a la fineza de Feijóo, por su brillante defensa de los hispanoamericanos, fué don José Mariano Gregorio de Eizalde Ita y Parra (mexicano), rector que había sido de la Real Universidad de México. Sus palabras son sinceras y sentidas cuando, en la "Aprobación" del tomo VI del Teatro crítico, dice: "Mayor empeño que el de censor es el en que me hallo, siéndome necesario mostrarme agradecido. Remítírseme el tomo VI del Teatro critico, que el autor pretende dar a luz, es sacarme a la luz en este teatro. Facilitando con el precepto una ocasión que si de muchos americanos es con noble envidia deseada para un corto desahogo de su reconocimiento, de mí, porque la coyuntura de hallarme presente en esta Corte lo ofrece, viene por dicha. Solamente agrada para insinuar el especial afecto con que al Rmo. Padre Maestro venero. Vindicó su Reverendísima a los ingenios americanos; ...aunque la permanente luz de sus ingenios ha sido bien manifiesta a todos desde el primer día de su descubrimiento, con todo nunca llegaron a acreditarse sus brillos... hasta que los colocó con su docta y erudita defensa este autor". 19

\section{HËRMENÉgILDO CoRBató, University of California at Los Angeles.}

\section{NOTAS}

1 Varios de los "españoles americanos" mencionados por Feijóo eran hijos de padre español $y$ madre mexicana ó peruana. Evidentemente, para él la ascendencia española, aun sólo por parte de padre, bastaba para la clasificación de "español americano". Las distinciones genealógicas no eran del agrado de su generoso espiritu. Respondiendo a don Salvador Mañer, quien en sa. Anti-Teatro había atacado la opinión de Feijóo sobre los hispanoamericanos, escribe: "Lo que de éstos nos dice el Sr. Mañer es derechamente opuesto a lo que nos refiere el Sr. D. Juan de Palafox en su Retrato Natural de los Indios. Y no hallando modo de conciliar a los dos, me resuelvo a conformarme antes con el dictamen de su Illma. que con el de su merced... Por tanto. aquella exacta distinción genealógica de Criollos, Gachupines, Mestizos, Quartetones, Saltatrases puede guardarla para mejor ocasión". Ilustración Apologética, Discurso XXXI, n. 19.

2 Teatro critico, II, discurso XV, n. 21. Para las citas de Feijóo en este artículo, aso la edición de sus obras hecha en Madrid en 1773. Me permito modernizar la ortografía. 
3 Teatro, IV, disc. VI, n. 1.

4 Jbid., n. 2.

5 Ibid., n. 3.

6. Ibid., n. 10.

7 Ibid., n. 21-23.

8 "Tales son el Padre Fr. Jaan de Totquemada en su Monarquía Indiana; Garcilaso de la Vega en sus Comentarios Reales de los Incas; el señor Don Lucas Fernández Piedrahita, Obispo de Panamá, en su Historia del Nuevo Reyno de Granada; el Padre Alonso de Ovalle en su Historia de Chile; Don José de Oviedo y Baños en su Historia de Venezuela; el Padre Manuel Rodriguez en su Historia del Marañón. A que podemos añádir Bartolomé Leonardo de Argensola en su Historia de la Conquista de las Molucas, y el eminentísimo Señor Cardenal Cienfuegos en la Vida que escribió de San Francisco de Borja, donde con la ocasión de baber sido el Santo autor de la Fundación de las Provincias de la Compañia del Perú y Nueva-España, llena dos capitulos enteros con elogios grandes de los ingenios de aquellos reynos". Teatro crítico, IV, disc. VI, n. 25.

9 Ibid., n, 27.

10 lbid., n. 28.

11 Citado por Feijóo, Ibid., n. 32.

12 Ibid., n. 33.

13 Cartas eruditas, V, carta X, n. 1.

14. V. Menéndez y Pelayo, Antologia de poetas hispano-ameticanos.

15 Teatro, 1, disc. XVI, n. 115.

16 V. Sarmiento, Demostración critico-apologética, II, disc. XXXI, S. VI (Madrid, 1779).

17 Citado por Sarmiento, Ibid., n. 457-459.

18 Antologia, I, xxxix.

19 Teatro, VI, p. xxiv. 